\title{
Traumatic Brain Injury Research in Brazil: A Bibliometric Study
}

\section{Pesquisa em traumatismo cranioencefálico no Brasil: um estudo bibliométrico}

\author{
Robson Luis Amorim ${ }^{1,2}$ Saulo Araújo Teixeira ${ }^{3}$ Sérgio Goncalves Silva-Neto ${ }^{1}$ Renato Anghinah ${ }^{1,2}$ \\ Manoel Jacobsen Teixeira ${ }^{1}$ Almir Ferreira de Andrade ${ }^{1}$ Wellingson Silva Paiva ${ }^{1,2}$ \\ 1 Neurosurgery Department, Hospital das Clínicas, Universidade de \\ São Paulo, São Paulo, Brazil \\ 2 Neurology Center, Hospital Samaritano, São Paulo, Brazil \\ Address for correspondence Wellingson Silva Paiva, MD, PhD, \\ Universidade de São Paulo, 470 Alves Guimarães St., Ap. 93, Pinheiros \\ - São Paulo, SP, Brazil - 05410-000 \\ 3 School of Medicine, Universidade Federal do Ceará, Barbalha, Brazil \\ (e-mail: wellingsonpaiva@yahoo.com.br).
}

Arq Bras Neurocir 2016;35:207-211.

\begin{abstract}
Keywords

- brain injuries

- bibliometrics

- craniocerebral trauma

- health services research

- Brazil

Resumo

Palavras-chave

- traumatismos encefálicos

- bibliometria

- serviços de saúde

- Brasil

Traumatic brain injury (TBI) is responsible for high rates of morbidity and mortality, constituting an important public health problem throughout the world. Improving medical research on systemic trauma is a critical issue to understand its impact and develop strategies for prevention and treatment. This paper presents an overview of medical research performed in Brazil about TBI comparing it with the production on the same topic with other countries and with publications about different neurological and non-neurological diseases. It is possible to notice that Brazil has a deficiency in the scientific production on TBI given its importance. Greater integration between the research centers could help meliorate the production and quality of the papers and encourage further studies on the theme, in the quest to minimize the shortage of publications that can be seen today.

O trauma cranioencefálico (TCE) é responsável por altas taxas de morbidade e mortalidade, constituindo um importante problema de saúde pública em todo o mundo. Melhorar a investigação médica sobre trauma sistêmico é uma questão crítica para compreender seu impacto e desenvolver estratégias para a sua prevenção e tratamento. Este artigo apresenta uma visão geral da pesquisa médica realizada no Brasil sobre TCE comparando-a com a produção sobre o mesmo tema com outros países e com publicações sobre diferentes doenças neurológicas e não neurológicas. É possível notar que o Brasil tem uma deficiência na produção científica sobre TCE dada a sua importância. Maior integração entre os centros de pesquisa poderia ajudar a aperfeiçoar a produção e a qualidade dos trabalhos e incentivar novos estudos sobre o tema, na busca de minimizar a escassez de publicações vista atualmente.
\end{abstract}

received

July 21,2015

accepted

August 28, 2015

published online

November 3, 2015
DOI http://dx.doi.org/

$10.1055 / \mathrm{s}-0035-1565261$. ISSN 0103-5355.
Copyright $@ 2016$ by Thieme Publicações License terms

Ltda, Rio de Janeiro, Brazil. 


\section{Introduction}

TBI is responsible for high rates of morbidity and mortality, constituting an important issue of public health throughout the world. ${ }^{1}$ This type of trauma includes a wide spectrum of severity, from injuries that lead the patient to death even before medical attention, to lighter impacts, for which victims seek emergency services. ${ }^{2,3}$ Only in the United States, there is a registered average of 1.7 million annual calls related to general trauma, causing $15 \%$ of all hospitalizations in the country and $30 \%$ of deaths by external causes. ${ }^{4}$ In the European Union countries, generalized injuries are responsible for the largest number of years of life with disability and are one of three major traumatic causes for cost generation to the health system. ${ }^{5}$

Developing nations, such as Brazil, which rely on a huge population of productive individuals to maintain a sustainable development, experience the highest increases in trauma statistics. In this context, the impacts of injuries like TBIs are even more harmful because of its potential risk of leading to temporary or permanent disability, precisely in the population with greater productive potential. ${ }^{6}$

In developed countries, although decreasing trend in the number of TBIs by traffic accidents is due to laws and preventative measures, simple falls are responsible for significant numbers of head trauma, especially in the older population. ${ }^{7}$ American data show that falls are the main mechanism of trauma attended, with $35.3 \%$ of the total, although transport accidents are still responsible for the majority of deaths by TBI. ${ }^{8}$ Particularly in low-and middleincome nations, where the increasing use of motor vehicles leads to more accidents and victims, the incidence of trauma grows sustainably. The influence of transport for these injuries is such that the World Health Organization (WHO) estimates that, in the year of 2020, traffic accidents will be the third leading cause of morbidity in the world. ${ }^{9}$

Gathering data and studying the epidemiology of systemic trauma is a critical issue for understanding the impacts of one of the most devastating public health problems around the world. With the data obtained, it is possible to trace targeted prevention strategies, identify priorities in education and research, and contribute to the needs of the emergency services ${ }^{10}$ and of patients who experience this type of injury. $^{11}$

Although medical research has had a significant increase in Brazil, especially over the last decade, ${ }^{11}$ the relevant publications on trauma seem to primarily stem from a few universities and hospitals. Given that TBI strongly affects all regions of Brazil, in this study, we proposed quantifying TBI research in Brazil as well as the profile of publications related to this theme. The results may help the scientific community and funding agencies to evaluate the current scenario of TBI research in Brazil and outline strategies for future studies and resource allocation.

\section{Methods}

We performed a database search through Medline, Lilacs, and SciELO for publications related to TBI over 4 years. The descriptors used were "traumatic brain injury," "craniocerebral injury trauma”, and "concussion." To identify the articles published in Brazil, we used the key words "Brazil" and "Brasil," in the field [Affiliation]. Duplicate studies were excluded. Also, we ran an active search for publications of the first authors' retrieved papers. Afterwards, two authors (RLOA and WSP) analyzed the articles and categorized them according to methodological design, to geographical range (separated by states), and chronology of the trauma (acute or chronic). In terms of the methodological design, they classified publications into observational, interventional, experimental, and review/meta-analysis studies. The studies involving patients sustaining TBI within 30 days were classified as "acute phase" studies. After this period, we considered the studies "chronic phase" studies. Abstracts presented at meetings or discussions were not included.

To render the comparison of TBI publications uniform across countries, we only used the Medline database for the same period (2007-2011). With this search strategy, we used the expression "traumatic brain injury" in the field [Title/ $A b s]$, in association with the name of other countries in the field [Affiliation], which indicates the authors' academic binding. Next, we used the same database to get the number of published papers in Brazil related to other clinical or surgical disease with high prevalence or relevant scientific interest. The search was performed using the keywords: "tumor", “diabetes", “stroke”, “asthma”, “osteoporosis", "brain tumor", "multiple sclerosis", "back pain", and "Alzheimer's," in the field [Title/Abs], associating it with the descriptor "Brazil" or "Brasil" in the field [Affiliation].

\section{Results}

We found 119 Brazilian TBI studies over a period of 5 years (-Fig. 1). Of these, 87 were published in Medline and 32 were published exclusively in Lilacs or Scielo databases. There was an average of 24.2 (19-29) articles published per year, mostly involving acute phase TBI (75.2\%). Concerning the type of study, the most prevalent was observational, represented by $69.5 \%$, followed by review studies (11.9\%), while $10.1 \%$ were experimental studies. Among the observational studies, $45.8 \%$ were cross-sectional, followed by case reports (18.1\%). There were 14 (16.9\%) prospective cohort papers and, among these, only one was a prevention study ${ }^{12}$ (-Fig. 2). Of the five interventional studies, three were clinical trials and two were case reports.

The Brazilian States with the highest absolute number of publications in the TBI were São Paulo (58), Santa Catarina (10), Minas Gerais (10) and Rio Grande do Sul (9). However, Santa Catarina was the state with the highest density of publication per 100,000 inhabitants $(0.157)$, followed by the Federal District (0.151) (-Fig. 3). In terms of absolute numbers of published papers in TBI research, Universidade de São Paulo (USP) was the leading center with 27 (22.6\%) published papers, followed by Universidade Federal de Minas Gerais (UFMG) with 6 (5\%), and another two institutions - Universidade Federal de São Paulo (UNIFESP), Universidade de Campinas (UNICAMP) and Universidade 


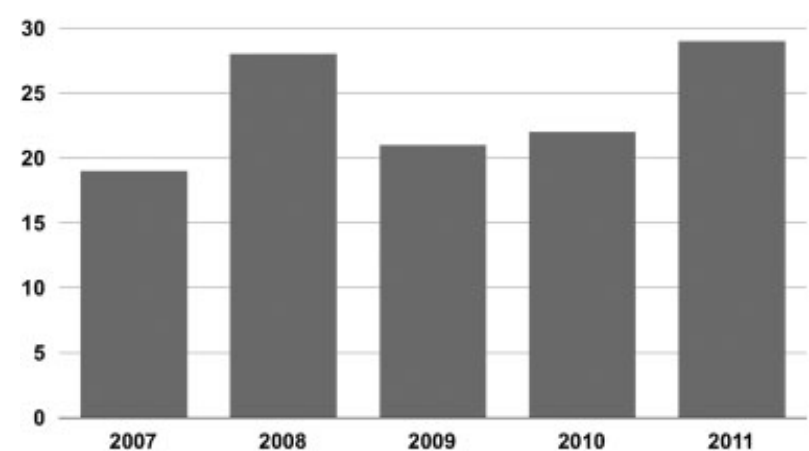

Fig. 1 Published papers on TBI in Brazil by year.

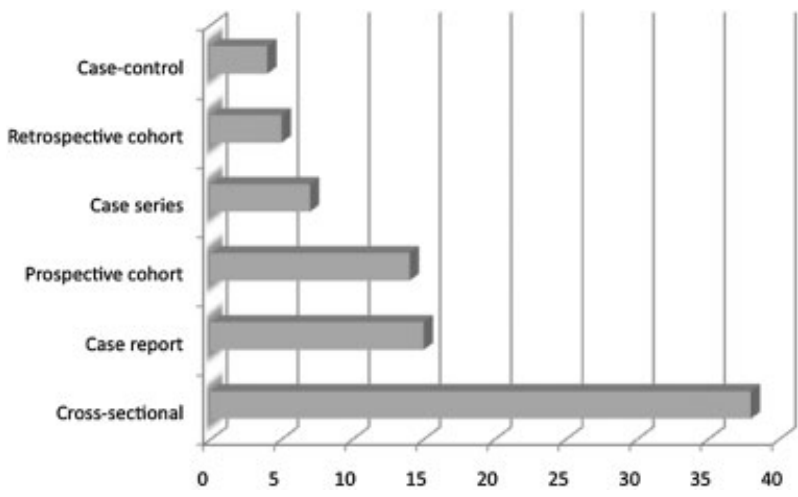

Fig. 2 Observational studies found by type.

Luterana do Brasil (ULBRA) - located in São Paulo State and Rio Grande do Sul State, with 5 (4.2\%) publications each. Most papers were published in Brazilian journals (55.4\%). Arquivos de Neuropsiquiatria, a Brazilian Medline indexed journal, published 23 (19.3\%) of all TBI papers, followed by Journal of Trauma with 8 (6.7\%). Four papers were published in Journal of Neurotrauma, the journal with the highest impact factor among all evaluated, and 20 (16.8\%) papers were published in journals with impact factor higher than 2.0, according to Thomson Reuters. ${ }^{13}$

In comparison with TBI publications in other countries, we found 2,861 papers published over these five years in the United States, followed by Australia with 338 publications. However, when we take into account the density of publications per 100,000 inhabitants from 2007 to 2011, Australia had the highest density (1.53), followed by Sweden (1.15), United States (0.9), and Canada (0.8). Brazil had a density of 0.02 (-Fig. 4).

In - Table 1, we present Brazilian literature on TBI, as well as on other clinical and neurological conditions.

\section{Discussion}

TBI research in Brazil is scarce in comparison to that of other countries. The number of searches performed in Brazil on head injury is small when faced with the United States, Europe, and Asia. There were 74.5 times more TBI studies/ inhabitants in Australia and two times more in South Africa than in Brazil. Moreover, when evaluating absolute data, Germany, with a population less than half the size of Brazils, ${ }^{14}$ produces around eight times more literature involving TBI. Again, Australia, despite being away from the axis of greater stimulus to scientific production (Europe and United States) and with a population of just over 22 million inhabitants, ${ }^{15}$ has a scientific production in the field of head injury ten times greater than Brazil.

Nevertheless, Brazil currently occupies the $15^{\text {th }}$ rank in SCImago scientific production, which ranks countries according to the number of publications and citations. ${ }^{13}$ In 2011, this scientific ranking tracked 13,122 articles published in the medical journals. As for general Neurosciences, the country reaches eleventh place in 2011, being responsible for the most expressive production in Latin America and the second in the southern hemisphere, following Australia. ${ }^{16}$

Furthermore, although TBI is a major Brazilian health problem, the number of papers published is notably small

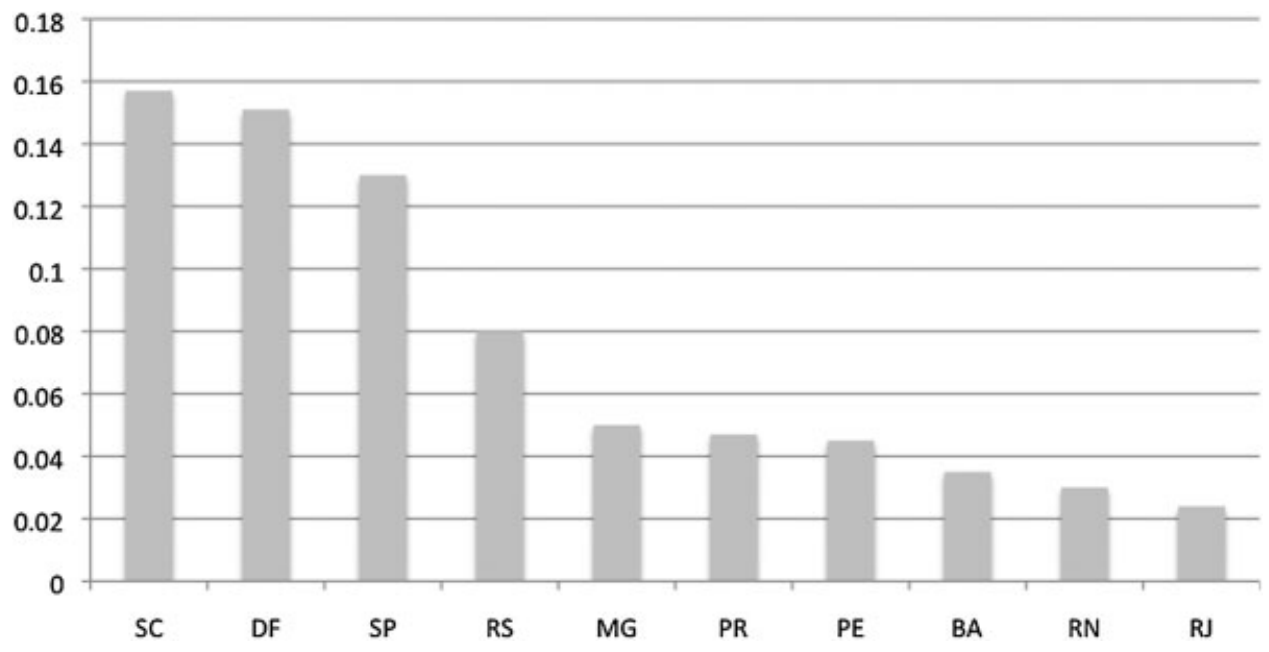

Fig. 3 Brazilian papers published on TBI by state (number of papers per 100,000 inhabitants). 


\section{TBI published papers}

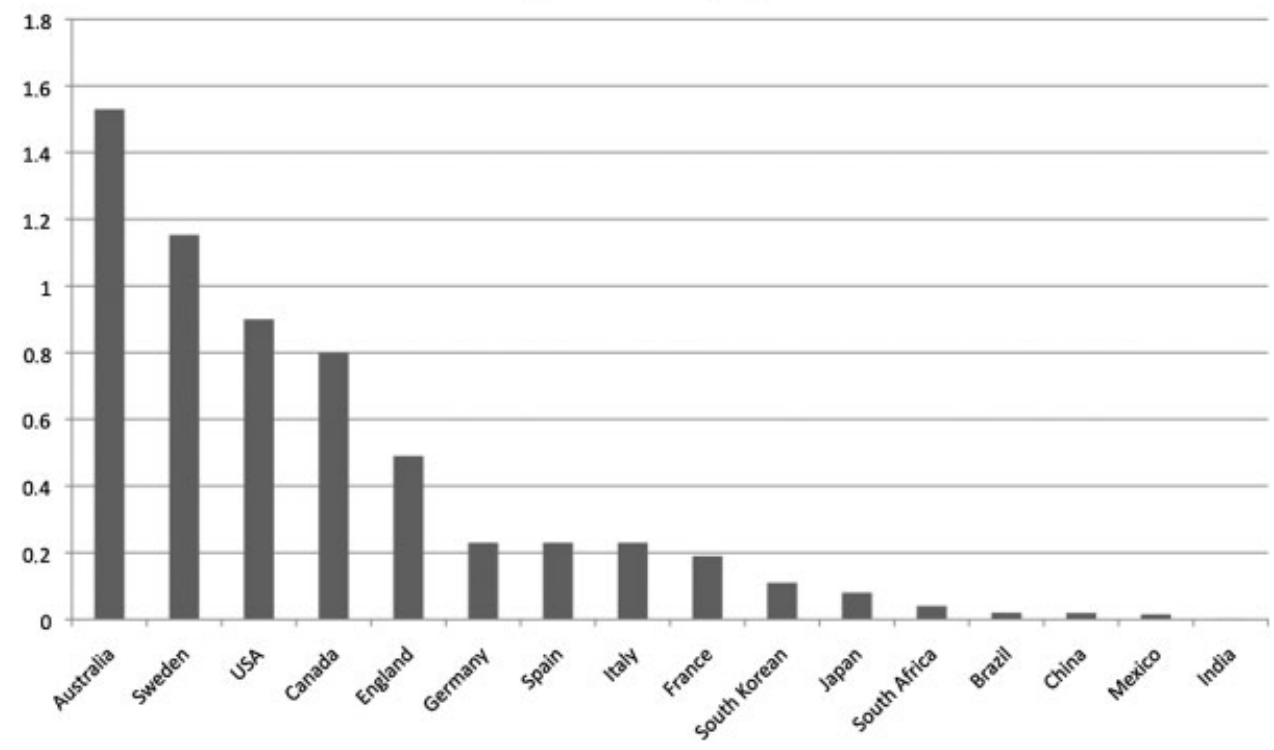

Fig. 4 Medline search of published papers on TBI among different countries (number of papers per 100,000 inhabitants).

in comparison to other high-prevalence neurological/clinical diseases in Brazil. For instance, the incidence of multiple sclerosis throughout life in the general population is slightly larger than five cases per 1,000 people, ${ }^{17}$ in contrast to TBI, with incidence rates reaching almost 300 cases per 100,000 inhabitants per year in developing countries. ${ }^{18}$ However, the Brazilian scientific production dedicated to multiple sclerosis is much higher than that dedicated to traumatic brain injury. Moreover, the incidence of oncology papers published in Brazil is more than 40-fold that of TBI, while stroke research is approximately seven folds higher. Among the possible reasons that may justify such data is the countrýs low investment in medical research on traumatic brain injury, especially when compared with resources allocated to other diseases, such as medical oncology and cardiovas-

Table 1 Results from Medline search for Brazilian papers on clinical and neurological diseases

\begin{tabular}{|c|c|}
\hline Descriptors & Number of papers \\
\hline "Tumor" and "Brazil" & 2,410 \\
\hline "Diabetes" and "Brazil" & 1,789 \\
\hline “Depression" and "Brazil” & 1,049 \\
\hline "Stroke" and "Brazil" & 432 \\
\hline "Asthma" and "Brazil" & 429 \\
\hline "Brain tumor" and "Brazil" & 350 \\
\hline "Osteoporosis" and "Brazil” & 182 \\
\hline "Alzheimer's Disease" and "Brazil” & 133 \\
\hline "Multiple sclerosis" and "Brazil” & 88 \\
\hline "Back pain" and "Brazil" & 60 \\
\hline "Traumatic brain injury" and "Brazil" & 59 \\
\hline
\end{tabular}

cular disease. ${ }^{19}$ Reduced funding for TBI research contrasts with the high amounts spent by SUS (The Brazilian Unified Health System) in the treatment of the victims. ${ }^{20}$

When assessing the quality and design of Brazilian TBI papers, the large amount of descriptive studies found is remarkable. The descriptive methodology was the most prevalent among TBI publications assessed in this study. Despite its importance, it represents the most viable option in an environment with restricted research incentive. Similarly, cross-sectional designs as well as case reports and case series, are faster and require less financial resources. Thus, it is possible to notice a scientific production curtailed by local circumstances. However, this seems to limit in fact the production of well-designed papers, since more than $70 \%$ were published in Medline database and almost 20\% were published in high impact journals. Nevertheless, research funds for producing high quality designs as clinical trials, cohort studies, and/or prevention studies should be pursued, to bring light to possible therapeutic strategies that may have greater and positive impact on the countrýs public health.

Resource allocation for research development is another fundamental issue that warrants consideration. This study shows a small scientific community in Brazil leading TBI research, based mostly out of the south and southwest of the country. Rodrigues et al. also found this distribution for cancer and cardiovascular diseases. One of the possible reasons is that TBI is a multidisciplinary area of research, where neurosurgeons, neurologists, biologists, nurses, physiotherapists, psychologists, among others, can interact and conduct different types of studies. ${ }^{20}$ A multidisciplinary and integrated team is most common in universities and postgraduation programs, with greater prevalence areas of Brazil with such institutions. However, this concentration limits a proper analysis of the subject at a national level, since the results may reflect the reality locally. ${ }^{21}$ 
Moreover, the concentration of research seemed in Brazil is very different from the population distribution and the incidence of TBI. The methodologies used are limited, as are the availability of human and financial resources for its implementation. When compared with other countries, there are surprising deficiencies concerning the absolute amount. As for other diseases, we observe a lack of incentive and a need to represent such disabilities. ${ }^{21}$

It is important to note several caveats regarding the present study. First, Medline database only retrieves information from the first authors. Therefore, the search does not include studies where Brazil does not appear in any of the Medline fields. This could partially explain the difference found in the two methodologies used to find Brazilian TBI papers published in Medline database over the five years ( 87 versus 59 papers). In addition, we did not assess another disease for comparison purposes, applying the same comprehensive research and methodology used to find TBI papers. However, the use of a "gross" Medline search showed an estimated value for use as an indicator of comparison. Moreover, to assess the quality of the papers published, we did not calculate the level of evidence of each study or the impact of the scientific output. Nevertheless, it may be possible to infer, based on study design type, indexing, and impact factor of the journal, where it was published. ${ }^{21}$

This study mapped TBI research in Brazil and, though superficially, was able to expose areas of scientific competence. TBI research in Brazil is scarce and underdeveloped, in contrast with its level of importance. Although Brazils medical scientific production has received important support in recent years, occupying a prominent position in South America, there is still a significant disparity between Brazilian production in comparison to other countrieś other medical fields. The present data can aid in the development of targeted interventions and definition of resource allocations. Greater integration between the major regional centers of medical research can help decrease the disparity in research and encourage further studies on the theme, in a quest to minimize the shortage of publications seen today.

\section{References}

1 Paiva WS, Andrade AF, Mathias Júnior L, et al. Management of supratentorial epidural hematoma in children: report on 49 patients. Arq Neuropsiquiatr 2010;68(6):888-892

2 Andrade AF, Paiva WS, Amorim RL, Figueiredo EG, Rusafa Neto E, Teixeira MJ. [The pathophysiological mechanisms following traumatic brain injury]. Rev Assoc Med Bras 2009;55(1):75-81
3 Neto HS, Neville IS, Beer-Furlan A, Tavares WM, Teixeira MJ, Paiva WS. Hemodynamic stroke caused by strangulation. Int J Clin Exp Med 2014;7(9):2932-2935

4 Tina M, Xu L, Wald MM, Coronado VG. Traumatic brain injury in the United States: emergency department visits, hospitalizations and deaths 2002-2006. Atlanta: CDC (Centers for Disease Control and Prevention), 2010

5 Moura JC, Rangel BLR, Creôncio SCE, Pernambuco JRB. Clinical and epidemiological profile of head trauma at the Urgências e Traumas Hospital in the city of Petrolina, Pernambuco. Arq Bras Neurocir. 2011;30(3):99-104

6 Leipziger D. The unfinished poverty agenda: why Latin America and the Caribbean lag behind. Finance Dev 2001;38(1):24-29

7 Butcher I, McHugh GS, Lu J, et al. Prognostic value of cause of injury in traumatic brain injury: results from the IMPACT study. J Neurotrauma 2007;24(2):281-286

8 Híjar-Medina MC, Carrillo-Ordaz CE, Flores-Aldana ME, Anaya R, López-López MV. [Risk factors for injuries caused by traffic accidents and the impact of an intervention on the road]. Rev Saude Publica 1999;33(5):505-512

9 Polinder S, Meerding WJ, Mulder S, Petridou E, van Beeck E; EUROCOST Reference Group. Assessing the burden of injury in six European countries. Bull World Health Organ 2007;85(1):27-34

10 Teixeira SA, Becco-Neto E, Ramos-Junior F, Rolim-Neto ML. Acute extradural hematoma in elderly: case report. Health Med 2012; 6(9):3216-3218

11 Jennett B. Epidemiology of head injury. J Neurol Neurosurg Psychiatry 1996;60(4):362-369

12 Salvarani CP, Colli BO, Carlotti Júnior CG. Impact of a program for the prevention of traffic accidents in a Southern Brazilian city: a model for implementation in a developing country. Surg Neurol 2009;72(1):6-13, discussion 13-14

13 SCImago. SJR - SCImago Journal and Country Rank. Available in http://www.scimagojr.com. Accessed on January 14, 2013.

14 Puvanachandra P, Hyder AA. Traumatic brain injury in Latin America and the Caribbean: a call for research. Salud Publica Mex 2008;50(1, Suppl 1):S3-S5

15 Australia Government. The Treasury. Australia's Demographic Challenges. Available in demographics. demographics.treasury. gov. Accessed on January 14, 2013.

16 Koizume MS, Lebrão ML, Mello-Jorge MHP, Primerano V. Morbidity and mortality due to traumatic brain injury in São Paulo city, Brazil, 1997. Arq Neuropsiquiatr 2000;58(1):81-9

17 Alonso A, Hernán MA. Temporal trends in the incidence of multiple sclerosis: a systematic review. Neurology 2008;71(2): 129-135

18 Guimarães JA. Medical and biomedical research in Brazil: a comparison of Brazilian and international scientific performance. Cien Saude Colet 2004;9(2):303-327

19 Maas AIR, Stocchetti N, Bullock R. Moderate and severe traumatic brain injury in adults. Lancet Neurol 2008;7(8):728-741

20 MacKenzie EJ. Epidemiology of injuries: current trends and future challenges. Epidemiol Rev 2000;22(1):112-119

21 Rodrigues PS, Fonseca L, Chaimovich H. Mapping cancer, cardiovascular and malaria research in Brazil. Braz J Med Biol Res 2000; 33(8):853-867 